\title{
Adapting Fiction into Film - Rashomon (1950)
}

PREETHAMOL M K

\section{Abstract}

Akira Kurosawa the Japanese film director is perhaps one of the most influential of filmmakers in the history of cinema. Rashomon (1950) directed by him is perhaps the best known Japanese film outside Japan. The film is an adaptation of two short stories by Akutagawa, the father of Japanese short story, namely In a Groove and Rashomon. My paper proposes to do a comparative study on how the genre of short story can be translated into a completely different medium of visual expression called the film by analysing the movie Rashomon. Has Kurosawa done a complete makeover with the original short stories? If yes, how far has he deviated from the original? What makes Rashomon such a special film and Kurosawa an ace moviemaker? These will be some of the basic questions under discussion in the paper.

Keywords: Fiction, Film, Intertextuality, Adaptation, Translation.

\section{Introduction}

Cinema always has the ability to transfer what is in the mind of the writer to a wider canvas. The versatility of the world of cinema from the point of view of a writer is extensive. What a work of fiction can do in terms of transferring it to another medium, especially the medium of cinema is brilliant. Thus, adaptation is a field, which makes critics all eager to discuss the extent to which one genre is faithful to the other. For such a topic of discussion, the article opines on the famed adaptation of Rashomon by Akira Kurosawa from two short stories by Akutagawa. The article begins with a discussion of the interdisciplinarity of novels, films and other genres of literature. It moves on to point out how adaptation and 


\section{Preethamol M K}

translation are considered subsections of intertextuality. The ensuing sections deal with Rashomon and how it owes its origin to two short stories. It goes on to discuss how the movie changed the future of Japanese movies and the pivotal role of Kurosawa in the realm of world cinema. The article ends with references to how adaptation is a specific process, which involves modification and alteration.

The confluence between cinema and literature is as old as the medium of cinema itself. Since cinema, in its development stages was considered as a low form of entertainment and in its urge and stint to get upgraded to and influenced by a larger and a more elite audience, films drew heavily from other arts like music, theatre and literature. Thus, there are cinematic translations of literary works and numerous other studies relating to the relationship between a literary work and its adaptation. Adaptation is the successful execution of a part or whole of a work that is written to a film. Twentieth century has several theories, which speak about the relationship of literature and film. Backed by cultural theories, film studies became legitimized in the academic circles as an academic discipline alongside literary and translation studies. It also strengthened the idea of interdisciplinarity of films, novels and other genres of literature. Such intertextual studies trace the route where stories are always derived from and how it has its basis in other stories.

Along with intertextaulity, translation is another means of exploring how art creates an art or how a creation could be greater than the original. The more an academic or student reads, the more will he be able to identify parallels and echoes in the main creations that he has encountered. Julie Sanders in her work Adaptation and Appropriation credits Robert Weimann who calls this process of works creating other works as 'reproductive dimension of appropriation' (1983: 14). It is 
noticeable that some translated works score better than their original ones and vice versa. When we talk of translation, the idea of fidelity is never far behind. It was Robert Stam, who brought a dialogical approach to film and literature. He was instrumental in exposing to a certain extent the concerns regarding the notions of fidelity between novels and films. Stam opines his ideas on fidelity in his article Beyond Fidelity: "The Dialogics of Adaptation that the shift from a single track, uniquely verbal medium such as film - makes fidelity in adaptation virtually impossible" (2000: 56).

Adaptation can be traced back to the early Greek playwrights like Euripides and Sophocles who based their stories on myths and legends, which the people of Greece already knew. Thus, it is not a new trend. Considering the various theoretical practices which emerged in the 1960s like structuralism and post-structuralism, we have theorists like Barthes who declared that 'any text is an intertext'. He argues further in his seminal essay Death of the Author that texts are not solely dependent on its authors for the derivation of meaning but a reader can create his own intertextual works. In this context, an acknowledgement is due to Julia Kristeva who formulated the term 'intertextualite' in her essay Word, Dialogue and Novel to mean the permutation of texts which she credited as a form of intertextuality. Adaptation involves cultural relocation, updating of a form or what is the focus in this paper as a movement into a new generic mode or context. Similar to adaptation, translation can be considered a subsection of intertextuality. Sometimes this shift can be less palpable, or at times more entrenched. But this does not mean that we are undermining the power of the original text. One thing, which is highlighted, is that adaptation, translation and intertextuality are constantly being affected by recent movements, readings and interpretations in the academic area. Homi Bhabha suggests how ideas are "repeated, relocated and translated in 


\section{Preethamol M K}

the name of tradition" (Bhabha 1994: 35). Thus, the correlation among adaptation, translation, intertextuality, postmodernism and even to the postcolonial notion of 'hybridity' is not strange and bizarre. Therefore, the whole genre is in a state of flux and the reproductive capacity of a work that is original can never be underestimated. Texts should generate other texts and should indulge in diverse forms of creativity, be it in literature as by way of translations or other creative genres like film or even performing arts. There will be a steady tension and dynamics between the original and latter creation. Thus, the term intertextuality should never be restricted to debates around literary arts.

Intertextuality as a theory gained popularity owing to the development of adaptation studies as a new academic discipline. We can trace the origin of adaptation studies to the film's intertextual relationship to that of literature. There will be not any harm if we link it to cultural studies even. Since we live in the multimedia environment of iPods, gaming consoles, smart phones, Kindles and High Definition television sets, intertextuality and adaptation studies become more part of our critical, cultural and academic deliberations. Texts are made available to us on the video and on computer screens and this opens up newly revealed arenas of the foregrounding of intertextuality of texts. It can also mean a pattern that is interdisciplinary which cuts across time, space and borders. It would not be wrong to assume in this context that nothing can exist on its own and there is similarity between texts and authors from different social and cultural contexts.

Rashomon has all the elements associated with translation, adaptation and intertextuality. Rashomon is a classic movie by the renowned Japanese filmmaker Akira Kurosawa that came out in the year 1950. It received the Grand Prize of the Venice Film Festival and the USA Academy Award for the best 
foreign film in 1951. It was based on two short stories by Akutagawa - Rashomon and In A Grove. These two stories give the film Rashomon its basic plot/plots (Encyclopedia Britannica). The script is based on and adapted from the short story In A Grove. Both the short story and the movie enumerate varied descriptions of a particular incident but is told from different perspectives. Kurosawa adopted the basic idea from the short story but thought it better to expand it and hence made use of Rashomon another story by Akutagawa. The film in its current version is a merging of the two. In Rashomon the story, we have a discharged servant who waits under the gate or the Rashomon for the weather to clear. He sees an old woman there who tries to steal hair from the corpses lying around, who aimed at making wigs with them as by way of living. The servant who has decided to become a thief knocks the old woman down, steals her cloths and runs away. Here we have the end of the story. In In A Grove we have multiple testimonies before the police about an incident and the story ends with no conclusion. In the film Rashomon we have Kurosawa making additions like introduction of a Commoner and the crying baby towards the end. He did not make a complete makeover with the short stories. Kurosawa renovated and adapted the content that he already had, transferring it into another form of personal expression that ultimately became the first film to gain an international recognition.

Akutagawa always questioned the values of morality but never gave answers. Kurosawa is also concerned with the ultimate truth and questions the reality about it. But he was also like Akutagawa never one to give answers to the truth he seeks. Both artists hurled their questions without the answers concerning truth and morality to the world they were offering their works to. We can say that the film rather dealt over with the existential despair over truth and morality, the tendency in 
humans to lie, matters concerning loss of faith in fellow beings and so on. Dealing with such themes during the 1950s, the film rose to an elevated level, which was powerful enough to harbor a special place in the realm of human mind.

Analyzing what makes Rashomon a masterpiece is directly linked with what makes Kurosawa an ace film director. Rashomon is deemed an iconic film mainly because of its novel treatment of its narrative orientation. It is a movie that is totally progressive in its nonlinear approach to narration - a crime involving four unreliable characters. Also the sequential takes of various scenes (like the woodcutter moving through the forest, the ruined old city gate of Kyoto through the haze of the heavy downpour of the torrential rains to name a few) was considered outstanding and hitherto unheard of in the history of cinema. What makes Kurosawa an ace director is he was courageous enough to take the risk and plunge into an unheard of film narrative style in the 1950s. The film brought Japan to the map of world cinema. In addition, the cinematography was iconic in that it made use of light and shadows to bring the desired effect.

The impulse in man to narrating stories is as old as language itself. There is a psychological impulse in all human beings of all cultures to create stories. The task of translating/adapting from a literary work to that of a screen acquires wider perspective when the original text is a short story as opposed to a novel or play. A novel needs omission or editing when transformed into a film. But the case of translating a short story into film, the brevity of the genre makes the film director expand the basic story. Considering the film Rashomon, the success of the film owes to Kurosawa the genius who reconfigured the language of cinema by his story-telling legacy. 
The film Rashomon is set in twelfth century Japan when famines and civil wars had devastated the capital. The focus is on the three characters - a Woodcutter, a Priest and a Commoner who are waiting under the Rashomon or the city gate for the rain to clear. The story then unfolds when the Woodcutter enumerates an incident he had witnessed in the forest that is about the murder of a Samurai. The Priest joins in when he mentions that he too had seen the Samurai and his wife in the forests some days afore. The rest of the story unfolds in flashbacks when we have the technique of multiple perspective narrative structure (for which the story is famous for) unfurling in black and white under the undeniable craftsmanship of the ace Kurosawa. Same incidents are repeated four times from four different angles, but rather than the story becoming clear, it only takes us to the labyrinth of confusion as to who is responsible for the murder of the Samurai.

Curiously enough, Kurosawa never gives us a logical conclusion as to who the real culprit is behind the murder of the Samurai. Thus, we have Kurosawa being indebted to Akutagawa in offering no conclusion to his story. Here Kurosawa is being faithful to his source of the story. To add a little bit of spice we have the wife of the Samurai being sexually assaulted by one of the narrators - the bandit, Tajomaru. The real reason why we have this alternate narration technique or better termed nonlinear narration, is may be to highlight the philosophical questions relating to reality and truth. Finally, we have the movie ending with an exclusive open closure giving us no clue as to ascertain the reality behind the murder of the Samurai, which seems to be the prime incident in the movie. What makes the film such a tantalizing experience is its refusal to endorse any of the witnesses account as a true one. 
Let us look at two prominent terms connected with the analysis of films and explore it in relation with Rashomon - the Montage and the mise en scene in the film. Montage is the juxtaposing of different images by editing. The Russian film director Sergei Eisenstein is considered to be one among the pioneers in this field of film aesthetics. He considered montage to be the essence of filmmaking. The best example for this in Rashomon is the Woodcutter's walk through the forest, with the shots of the rays of the sun falling on him through the trees, a close up shot of his axe - all in a sequence of equal duration, shot in different shots, set to the back ground of a brooding score which upholds the overall effect of the montage shots in contrast. We find the effect of the metric montage more appealing. In common man's term montage refers to having a series of shots which are edited and sequenced in a series for a variety of purposes ranging from condensation of time, space and information. Again, montage is a style in which two or more independent shots are juxtaposed to create a new idea that did not previously exist. It is the latter method that made Kurosawa and his movies special and Rashomon is no exception.

What makes Rashomon such a special film is its then novel experiment with form and narration. The presentation of the story in distinct visual motif makes it such a brilliant example for considering film an apt medium for storytelling. The film did a laudable task in trying to delineate the relativity of truth. Any feature that contributes to the visual element of a film can become part of what is termed as the mise en scene of the film. They work together to weave the story. In Rashomon we have scenes of mise en scene depicting the innermost turmoil of characters. It provides a depth that goes beyond the scope of an ordinary narrative. Mise en scene helps in creating scenes, which go a step beyond ordinary narrative. Let us look at the final scene in the film, where the Woodcutter is pacing back 
and forth. Torrential rains reflect the inner most disturbance of his mind. Techniques like this go a long way in storytelling. Multiple narrative techniques and methods can thus be rolled into one and be exhibited in a single piece like film.

No art form can stand without mutual borrowing and lending. The arena of film is no exception. The inane thread of a film can most of the times be traced back to another film, a book or another art form which appeals to the general public because of its popularity. If we analyze a great number of films, their original source can be a literary text from where the writer has actively or passively, consciously or unconsciously borrowed. Kurosawa borrowed for his Rashomon from Akutagawa. Instead of being limited to one medium, borrowing from other sources and thus being indebted to other sources gives films the status of blending with other media and art forms.

\section{Conclusion}

As by way of conclusion, there exists a vibrant relationship between the world of cinema and literature. There is no doubt that adaption of literary texts is one of the most popular forms of film making that gives rise to intertextual reading of films. One genre gives the other a chance to adapt and adopt itself to the nuances of the other. Adaptation is a specific process, which involves a multitude of routes comprising of modification and alteration of one genre to another: novels into films, prose narrative into prose fiction or even the transition of a drama into narrative. The popularity of this field is so much that we have modules in higher education programs which analyses the different genres of literature and films and what all consorts to the difference between them. Adaptation should never be about making polarized judgments. We should never judge if the original was good or the adapted version better. It should be about analyzing the processes, ideologies and methodologies involved in this intertextual relationship. 
Preethamol M K

\section{References}

Allen, Graham. 2000. Intertextuality. New York: Routledge.

BASSNETt, SUSAN. 1993. Comparative Literature: A Critical Introduction. Oxford: Blackwell Publishers.

BhaвHA, Homi. 1994. The Locations of Culture. London: Routledge.

Kurosawa Akira. (1950). Rashomon. Perf. Toshiro Mifune, Machiko Kyo, Masayuki Mori. Daiei Motion Picture Company. DVD.

MonACO, JAMES. 2000. How to Read a Film: The World of Movies, Media and Multimedia. Oxford: Oxford University Press.

Prince, StePhen. 1999. The Warrior's Camera: The Cinema of Akira Kurosawa. Princeton: Princeton University Press.

STAM, RoBerT. 2006. Literature through Film: Realism, Magic, and the Art of Adaptation. Peking: Peking University Press.

THE EDItors OF ENCYClOPAEDIA BRITANNICA. 2018. Ryūnosuke Akutagawa's Rashōmon. Encyclopædia Britannica. https://www.britannica.com/topic/Rashomonby-Akutagawa-Ryunosuke (Accessed 2020-12-01).

Yoshimoto, Mitsuhiro. 2000. Kurosawa: Film Studies and Japanese Cinema. Durham: Duke University Press.

***

\section{Cite this Work:}

M K, PREeTHAMOL. 2020. Adapting Fiction into Film - Rashomon (1950).

Translation Today, Vol. 14(2). 135-144. DOI:10.46623/tt/2020.14.2.ar8 